\title{
Erratum: Opportunities and Challenges in Omics
}

\author{
MingMing Ning $\cdot$ Eng H. Lo
}

Published online: 11 January 2011

(C) Springer Science+Business Media, LLC 2011

Erratum to: Transl. Stroke Res. (2010) 1:233-237

DOI 10.1007/s12975-010-0048-y

Due to an error in production, reference \#8 was reproduced incorrectly in the reference list of this editorial. The reference is correctly reproduced below.

8. Ning M, Sarracino DA, Buonanno FS, Krastins B, Wang X, Chou S, McMullin D, Lopez M, and Lo EH. Proteomic protease substrate profiling of tPA treatment in acute ischemic stroke patients. Transl Stroke Res. 2010. doi:10.1007/s12975-010-0047-Z

Springer apologizes for the error.

The online version of the original article can be found at http://dx.doi. org/10.1007/s12975-010-0048-y.

M. Ning $(\bowtie) \cdot$ E. H. Lo $(\bowtie)$

Clinical Proteomics Research Center and Neuroprotection,

Research Laboratory, Departments of Neurology and Radiology,

Massachusetts General Hospital and Harvard Medical School,

Boston, MA, USA

e-mail: Ning@hms.harvard.edu

E. H. Lo

e-mail: Lo@helix.mgh.harvard.edu 